\title{
Numerical Simulation o Shell and Tube Heat Exchanger using Ansys Fluent
}

\author{
Kamala Priya B, B Udaya Lakshmi, A Hari Krishna
}

\begin{abstract}
From the current situation, the Heat Exchangers uses extreme commonly are tube and Shell heat exchangers. The most usual uses of Shell and tube heat exchangers are electricity creation, cooling system of hydraulic fluid, oil in motors, transmissions, and hydraulic power packs. Shell and tube heat exchangers are made of the casing using a bunch of tubes with inside. The desirable outcome of the paper is to figure out the speed of heat transport using hot water as the hot liquid. The target of this paper is to mimic a tube and shell heat exchanger and also to assess blood flow and temperatures from the tubes and shell by employing applications tool Ansys. The simulation is composed of modeling and meshing cross section of tube and shell heat exchanger utilizing computational fluid dynamics (CFD).
\end{abstract}

KEYWORDS:Shell and tube heat exchanger, Catia, Ansys CFD Fluent, Temperature.

\section{INTRODUCTION}

Heat exchangers are termed by their various software.as an instance, to accelerate the liquid by utilizing heat exchangers are called condensers, in precisely the exact same style, heat exchangers taken for function of boiling are referred to as boilers. Functioning and efficacy of heat exchangers are calculated via the quantity of heat transferred with region of transport of heat and fall of stress. A superior launch of its own efficacy is carried out by calculating a complete heat transfer coefficient. Stress drop and cross-sectional region are needed for some quantity of heat transport, supply a running price and essentials of the ability of a heat exchanger. A heat exchanger is a device used to move heat between two process flows or fluids which involve heating, heating, cooling, steaming or evaporation.

Process heat transport addresses the degrees of heat market as they happen in the heating gear of the technology procedure. This methodology communicates to better concentrate on the significance of the temperature comparison between the origin and the recipient. Different heating exchangers are modeled for all various industrial processes and software. Assessing the impact of different operational temperatures for locating out the heat transport speed at specific temperatures have been directed with Kamala Priya $\mathrm{B}(1)$ and the outcomes are observed to

Revised Manuscript Received on September 15, 2019.

Kamala Priya B: Assistant Professor, Mechanical Engineering Department, Lakireddy Bali Reddy College of Engineering, Mylavaram, Krishna District, A.P

B Udaya Lakshmi: Assistant Professor, Mechanical Engineering Department, Lakireddy Bali Reddy College of Engineering, Mylavaram, Krishna District, A.P

A Hari Krishna: Student, Mechanical Engineering Department, Koneru Lakshmaiah Educational Foundation, Vaddeswaram, Guntur District, A.P.

function, that warm socket temperatures of shell and Tube Heat Exchanger has contributed a more rapid solution. The speed of growth of heat transfer speed as a result of reduced specific heat and higher density, higher temperature supply and big surface quantity of Nano particles have been introduced with Dr.M.Sakthivel et al(2). Vindhya vasini Prasad dhubey et al(3) was designed a computer model with Ansys 14.0 and conducted steady state thermal simulation using a number of thermal loading on distinct faces and borders.. The design of Shell and Tube heat exchanger using Kerns method and carried out the steady state thermal analysis using Ansys 14.0 have been tested by Vindhya Vasini Prasad Dhubey(4) under various flow conditions considering the insulations of aluminum foil, cotton wool, tape, foam, paper etc.Through different constructional details, design methods and the reasons for the wide acceptance of Shell and Tube type Heat exchangers has been described by Kuldeep Singh(5).

\section{OBJECTIVE}

The objective of this paper is to model the Shell and Tube Heat Exchanger and to study the flow and temperatures inside the Shell and Tube heat exchanger.

\section{METHODOLOGY}

The flow and temperature of Shell and Tube are calculated using Ansys Software.

\section{Modeling:}

The world's engineering and design leading software for product 3D CAD design excellence was CATIA where it is used to design, simulate, analyze, and manufacture products in a variety of industries including aerospace, automotive, consumer goods, and industrial machinery. In the present work, the shell and tube heat exchanger model as shown in Fig 1. has been taken from Dr.M.Sakthivel (2) where the specifications given are as follows.

\section{Specifications of the STHE}

Table 1shows the specifications of the STHE

\begin{tabular}{|l|l|}
\hline Specification & Dimensions (mm) \\
\hline Length of heat exchanger & $1500 \mathrm{~mm}$ \\
\hline No of tubes & 07 \\
\hline Diameter of inner shell & $138 \mathrm{~mm}$ \\
\hline Diameter of outer shell & $140 \mathrm{~mm}$ \\
\hline Diamete of inner tube & $20 \mathrm{~mm}$ \\
\hline Diameter of outer tube & $22 \mathrm{~mm}$ \\
\hline No of baffles in STHE & $05 \mathrm{ng}$ \\
\hline $\begin{array}{l}\text { Distance between the } \\
\text { baffles in STHE }\end{array}$ & $250 \mathrm{~mm}$ \\
\hline
\end{tabular}




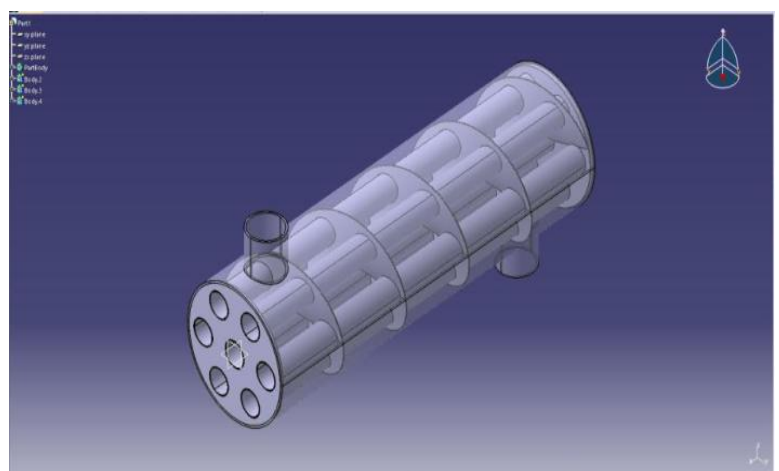

Fig 1: Modeling of Shell and Tube Heat Exchanger

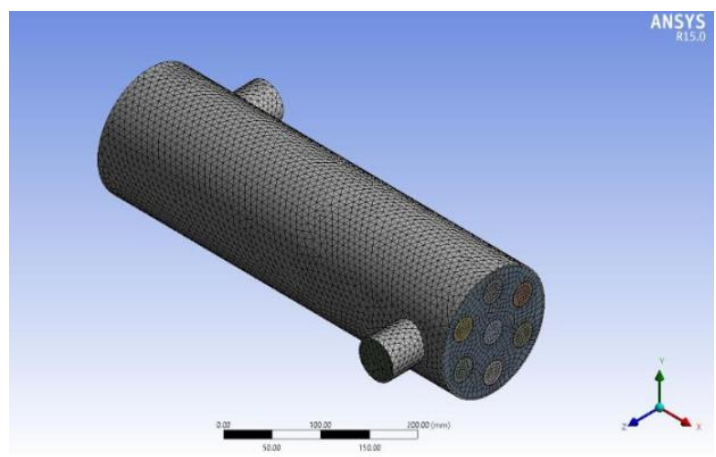

Fig 2: Meshing of Shell and Tube Heat using CATIAExchanger using ANSYS"

\section{Meshing:}

«ANSYS Meshing is a general-purpose, intelligent, automated high-performance product. It produces the most appropriate mesh for accurate, efficient multi physics solutions. ANSYS Meshing is aware of the type of solutions that will be used in the project and has the appropriate criteria to create the best suited mesh. For a quick analysis or for the new and infrequent user, a usable mesh can be created with one click of the mouse. Fig 2 shows the meshing of SHTE where three node triangle mesh was used using Ansys ».

\section{Boundary Conditions:}

«Different boundary conditions were applied for different zones. Since it is a shell-and-tube heat exchanger, there are two inlets and two outlets. The inlets were defined as velocity inlets and outlets were defined as pressure outlets. The inlet velocity of the cold fluid was kept constant i.e. $0.0787 \mathrm{~m} / \mathrm{s}$, whereas velocity of hot fluid was kept constant i.e. $1.594 \mathrm{~m} / \mathrm{s}$. The outlet pressures were kept default i.e. atmospheric pressure. The hot fluid temperature at inlet was $340 \mathrm{k}$ and cold fluid inlet temperature was kept $300 \mathrm{k}$. The other wall conditions were defined accordingly. The surrounding air temperature was kept 300k ».

\section{Analysis:}

«Computational Fluid Dynamics (CFD) is a tool with amazing flexibility, accuracy and breadth of application. ANSYS Fluent and ANSYS CFX provide fast results for virtually any fluid or multiphysics application, with industry-leading accuracy and robustness. This serious CFD software has the wide ranging capabilities needed to solve your design problems today and in the future. CFD solvers extend the limits of what is possible so you can maximize your product's performance and efficiency »

\section{RESULTS AND DISCUSSION}

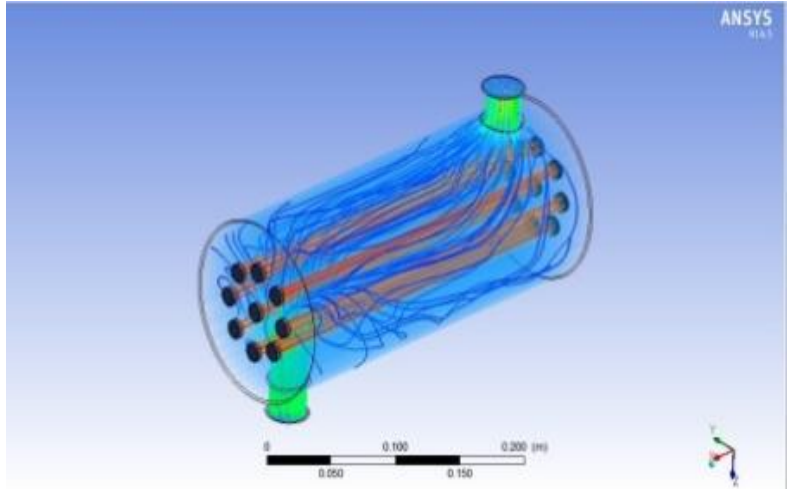

Fig 3: Flow of fluids in SHTE

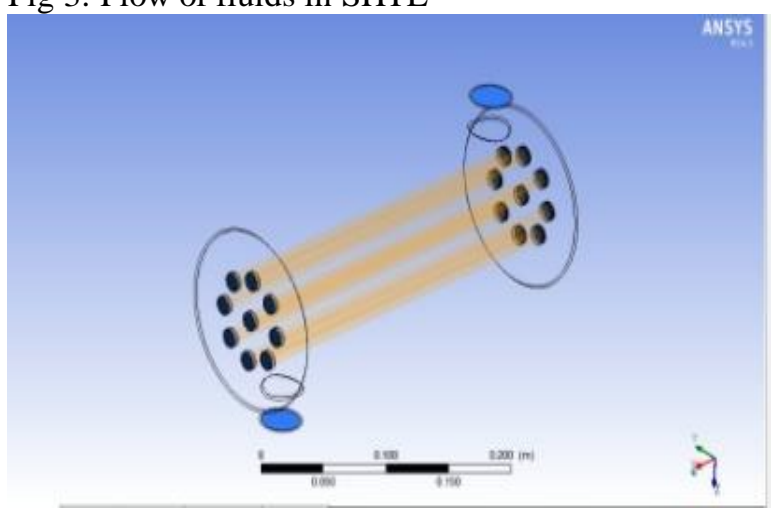

Fig 4: Flow of fluid in Tubes of STHE

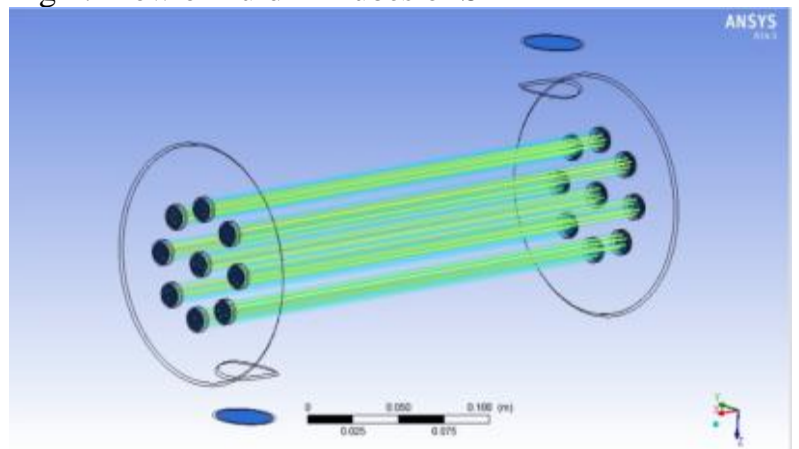

Fig 5: Flow of Tube fluid after Heat exchange

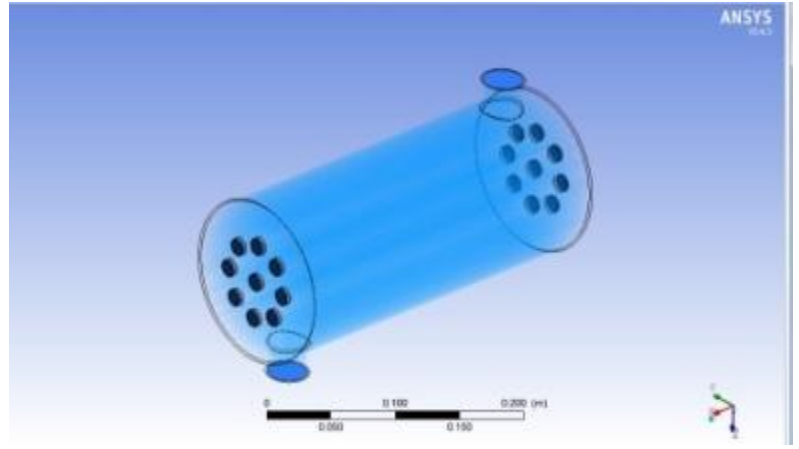

Fig 6: Flow of fluid in shell of STHE 


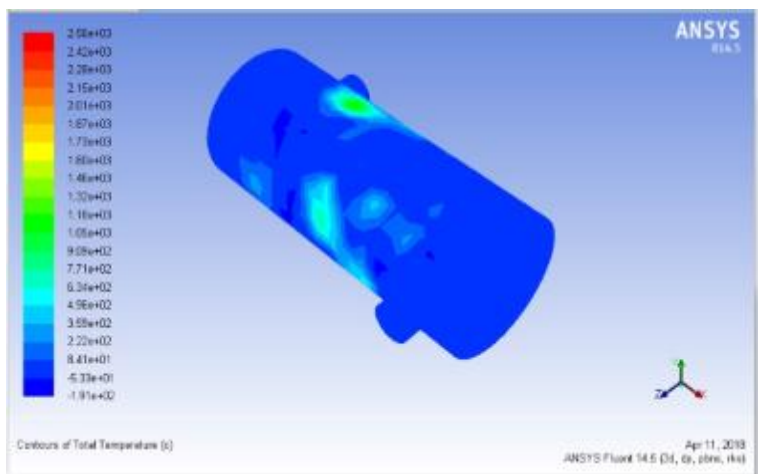

Fig 7: Contours of Temperature

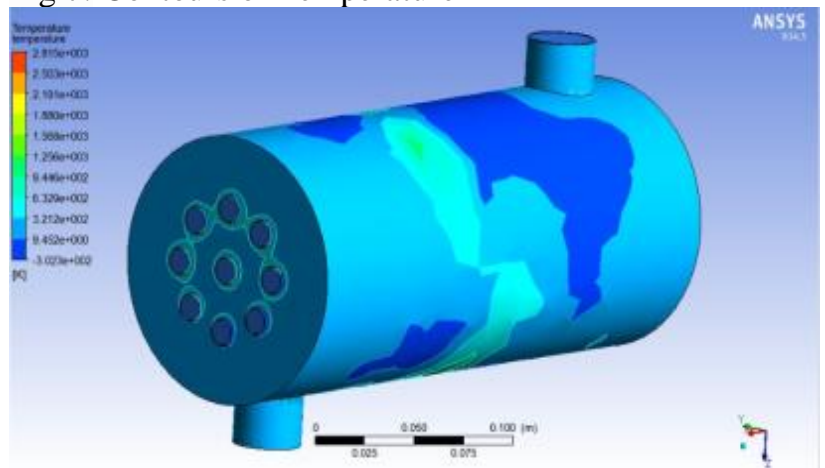

Fig 8: Temperature distribution of STHE

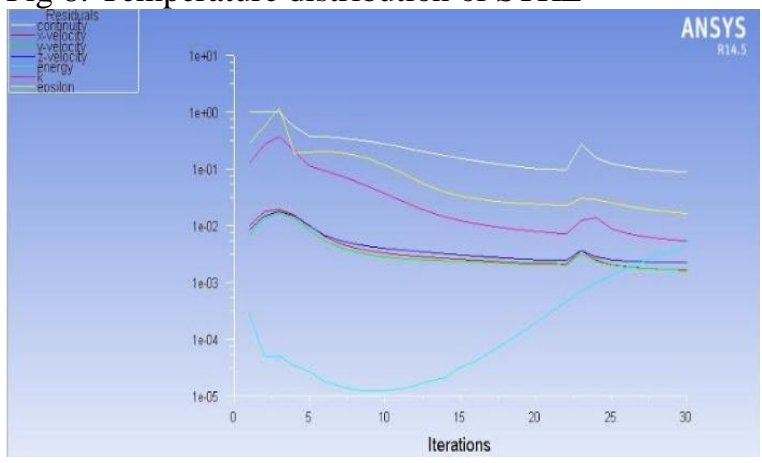

Fig 9: Iterations of Velocity and Temperature

« Fig 3,4,5,6 shows the flow of fluids in Shell and Tube Heat Exchanger and in tubes of Shell and Tube Heat Exchanger respectively. Fig 7 and fig 8 describes the contours of temperature and temperature distribution of Shell and Tube Heat Exchanger respectively.30 iterations of velocity and temperature can be observed from Fig 9 ».

\section{For temperature:}

\begin{tabular}{|c|c|c|c|}
\hline S.NO & $\begin{array}{c}\text { Inlet } \\
\text { Velocity of } \\
\text { hot fluid } \\
\text { (water) } \\
\text { (m } \text { m/s) }\end{array}$ & $\begin{array}{c}\text { Inlet Temp } \\
\text { of } \\
\text { hot water(in } \\
\text { Kelvin's) } \\
\text { I/h.max }\end{array}$ & $\begin{array}{c}\text { Outlet Temp } \\
\text { of } \\
\text { hot water(in } \\
\text { Kelvin's) } \\
\text { I } \text { /h.min }\end{array}$ \\
\hline 1 & 0.155 & 366 & 354.568 \\
\hline 2 & 0.11 & 375 & 345.597 \\
\hline 3 & 0.154 & 377 & 352.235 \\
\hline 4 & 0.156 & 375.5 & 354.125 \\
\hline 5 & 0.22 & 378.9 & 364.258 \\
\hline 6 & 0.35 & 390 & 359.289 \\
\hline 7 & 0.37 & 392 & 358.647 \\
\hline
\end{tabular}

Table 2: CFD results for temperature
The above table discusses the CFD results for temperatures at different velocities.

\section{CONCLUSION}

In the preceding analysis, it's discovered that the temperatures and flow within theShell and Tube of both Shell and Tube Heat Exchanger have been all calculated. The temperatureof warm water in inlet zone will be raised as the speed increase and the temperatures of warm water at socket will be diminished as the speed increases.

\section{FUTURE SCOPE}

Within this undertaking, temperature effects were decided depending on the use of Ansys Fluent instrument. By analyzing the properties ofdiverse materials, opportunity to modify the properties of these substances in tube and shell to improve heat transfer speed and total coefficient via CFDanalysis

\section{REFERENCES}

1.KamalaPriya B, "Effect of Operational Temperatures in Efficiency of Shell and Tube Heat Exchanger" ISSN 2229-5518.

2. Sawant, S., More, S. E., \& Dange, H. Design, Development and Performance Analysis of Anticorrosive Heat Exchanger.

3. Dr. M Sakthivel, "FLUENT ANALYSIS OF SHELL AND TUBEHEAT EXCHANGER USING NANOFLUIDS”, ISSN Online: 0976-6359.

4. Owaid, A. I., Tariq, M., Issa, H., Sabeeh, H., \& Ali, M. The Heat Losses Experimentally in the Evacuated Tubes Solar Collector System in Baghdad-Iraq Climate.

5.Vindhya,asiniPrasad,Dubey,RajRajatVerma,PiyushShankerVerma,A.K.Sriv astava," Steady State Thermal Analysis of Shell and Tube Heat Exchanger to demonstrate the Heat Transfer capabilities of various Thermal Materials using Ansys" ISSN:0975-5861.

6. Elhabib, O., Ayad, M., Elmasry, A., \& Omar, A. A. Heat Treatment of Wear Particles of Automotive Engines to Determine their Materials from Temper Colours.

7.Vindhya VasiniPrasad, Dubey, RajRajatVerma, PiyushShankerVerma, A.K.Srivastava," Performance Analysis of Shell and Tube Heat Exchanger under the effect of varied Operating Conditions", E-ISSN:2273-1634.

8. Jakkula, S. U. B. O. D. H., \& Sharma, G. S. (2014). Analysis of a Cross Flow Heat Exchanger Using Optimization Techniques. International Journal of Applied Engineering Research and Development (IJAERD), 4(6), 1-10.

9. KuldeepSingh ," An overview of Shell and Tube Heat Exchangers “, p-ISSN:2349-6002 .

10. Kumar, R., Pedgopu, V., Kumar, A. N. I. L., Thakur, R. O. B. I. N., \& Pundir, A. N. I. L. (2013). CFD based analysis heat transfer and friction characteristics of broken multiple rib roughened solar air heater duct. Int J Mech Prod Eng Res Dev, 3, 165-172.

11. Mahrous, A. (2013). Thermal performance of PCM based heat sinks. Int J Mech Eng, 2(4). 